\title{
Purified Protein Derivative of Mycobacterium tuberculosis and Excretory-Secretory Antigen(s) of Toxocara canis Expand In Vitro Human T Cells with Stable and Opposite (Type $1 \mathrm{~T}$ Helper or Type $2 \mathrm{~T}$ Helper) Profile of Cytokine Production
}

\author{
Gianfranco F. Del Prete, Marco De Carli, Cataldo Mastromauro, Roberta Biagiotti, Donatella Macchia, \\ Paolo Falagiani, * Mario Ricci, and Sergio Romagnani \\ Division of Clinical Immunology and Allergology, Istituto di Clinica Medica 3, University of Florence, \\ I-50134 Florence, Italy; and ${ }^{*}$ Lofarma Allergeni, I-20100 Milan, Italy
}

\begin{abstract}
A large series of $T$ cell clones (TCC) specific for purified protein derivative (PPD) of Mycobacterium tuberculosis (total 60) or Toxocara canis excretory/secretory (TES) antigen (total 69) were established from the peripheral blood of two healthy individuals and analyzed for their profile of cytokine production in response to stimulation with either the specific antigen or the polyclonal activator phorbol myristate acetate plus anti-CD3 antibody. Under both these experimental conditions, the great majority of PPD-specific TCC secreted IL-2 and IFN- $\gamma$ but not, or limited amounts of, IL-4 and IL-5. In contrast, most TES-specific TCC secreted IL- 4 and IL-5 but not, or limited amounts of, IL-2 and IFN- $\gamma$. PPD-specific TCC that failed to secrete IL-4 and IL-5, and TES-specific TCC that failed to secrete IL-2 and IFN- $\gamma$, were found to lack transcripts for IL-4 and IL-5, or for IL-2 and IFN- $\gamma$, respectively. During the course of the study, over a 6-mo period, the functional phenotype of both TES- and PPD-specific TCC was repeatedly assessed and remained constant.

These data demonstrate that $T$ cells with stable Th1 or Th2 functional pattern exist not only in mice but also in humans and suggest that in the course of natural immunization certain infectious agents preferentially expand $T$ cell subsets with stable and definite profile of cytokine production. (J. Clin. Invest. 1991. 88:346-350.) Key words: human type $1 \mathrm{~T}$ helper and type $2 \mathrm{~T}$ helper clones $\cdot$ IL-2 $\cdot$ IFN- $\gamma \cdot$ IL-4 $\cdot$ IL-5
\end{abstract}

Address correspondence to Professor Sergio Romagnani, Istituto di Clinica Medica 3, Viale Morgani, 85, I-50134 Firenze, Italy.

Received for publication 19 February 1991 and in revised form 5 April 1991.

1. Abbreviations used in this paper: APC, antigen-presenting cell; DTH, delayed type hypersensitivity; Mt, Mycobacterium tuberculosis; $\mathrm{PB}$, peripheral blood; $\mathrm{PPD}$, purified protein derivative; rIL-2, recombinant IL-2; SN, supernatants; Tc, Toxocara canis; TCC, T cell clones; TCL, T cell lines; TCR, T cell receptor; TES, Toxocara canis excretorysecretory antigens; Th1 and Th2, type 1 and type $2 \mathrm{~T}$ helper.

J. Clin. Invest.

(c) The American Society for Clinical Investigation, Inc.

0021-9738/91/07/0346/05 \$2.00

Volume 88, July 1991, 346-350

\section{Introduction}

Mouse $\mathrm{CD}^{+}$helper $\mathrm{T}$ cells have been distinguished by their cytokine production profiles into two distinct and mutually exclusive subsets. Type $1 \mathrm{~T}$ helper (Th1) ${ }^{1}$ cells produce IL-2, IFN- $\gamma$, and TNF- $\beta$, whereas type 2 T helper (Th2) cells secrete IL-4, IL-5, IL-6, and IL-10 $(1,2)$. In addition to T cell clones (TCC) that fit in the Th1 or Th2 group, murine $\mathrm{CD}^{+} \mathrm{TCC}$ have been described that have the capacity to produce virtually every known lymphokine (3). These clones, designated $\mathrm{Th} 0$, probably represent an intermediate step in the differentiation of naive $\mathrm{T}$ cells into $\mathrm{Th} 1$ or $\mathrm{Th} 2$ cells following the antigen/antigen-presenting cell (APC) signals that they receive (3-5).

The majority of human $\mathrm{CD}^{+} \mathrm{TCC}$ derived from the peripheral blood (PB) of healthy donors do not fit into the Th1 and $\mathrm{Th} 2$ lymphokine production patterns of murine $\mathrm{CD}^{+}{ }^{+} \mathrm{T}$ cells, but resemble more the "Th0-like" pattern described for TCC obtained from nonimmunized mice $(6,7)$. However, subsets of human $\mathrm{CD}^{+} \mathrm{T}$ cell clones resembling $\mathrm{Th} 1$ or Th 2 mouse TCC have been isolated from tissues of patients in different disease situations (8-11), suggesting that selection of $\mathrm{CD} 4^{+} \mathrm{T}$ cells with stable Th 1 or Th 2 cytokine production phenotypes may be a property related to the structure of antigen and/or to the conditions of immunization.

In an attempt to provide additional information on the mechanisms responsible for the differentiation of human $T$ cells into defined Th phenotypes, our strategy has been to establish TCC specific for purified protein derivative (PPD) from Mycobacterium tuberculosis (Mt) or Toxocara canis (Tc) excretory-secretory (TES) antigens by using PBL from the same healthy individuals. Exposure to $\mathrm{Mt}$ is indeed frequent in the Italian population, even if in the majority of cases it results in natural immunization without overt disease. Likewise, human toxocariasis is quite rare, but positive levels of anti-Tc antibodies have been found in $2-3 \%$ of the adult population and $7-14 \%$ of school age children (12), and PBL from most healthy individuals, apparently without history of Tc infestation, exhibit strong proliferation in response to TES (unpublished data). More importantly, infection with Mt and infestation with $\mathrm{Tc}$ induce different types of immune responses that may be consistent with the selective activation (or differentiation) of Th1- or Th2-like cells, respectively. Infection with Mt usually results in delayed type-hypersensitivity (DTH), whereas in- 
festation with Tc can induce increased IgE levels and eosinophilia (13).

When cytokine secretion patterns of a wide series of PPDand TES-specific TCC were assessed, a clear-cut difference in the profile of cytokine production was observed. Virtually all PPD-specific TCC expressed a Th1-like profile, whereas the great majority of TES-specific TCC displayed a Th2-like pattern. These results are consistent with the possibility that $T h 1$ and Th2 phenotypes represent a specific property of TCC selected by peculiar antigens.

\section{Methods}

Donors. PBMC were obtained from two individuals aged 29 and $42 \mathrm{yr}$, respectively, without history of overt tuberculosis or toxocariasis, but showing both DTH skin reaction to PPD and in vitro proliferative response of their PBL to TES antigen.

Reagents. PHA was purchased from Gibco Laboratories, Grand Island, NY, and phorbol myristate acetate (PMA) from Sigma Chemical Co., St. Louis, MO. Recombinant IL-2 (rIL-2) was kindly provided by Glaxo, Geneva, Switzerland. Human IL-5 was purchased from Amgen Biologicals, Thousand Oaks, CA. OKT3 (anti-CD3), OKT4 (antiCD4), and OKT8 (anti-CD8) MAb were purchased from Ortho Pharmaceutical, Raritan, NJ. PPD was kindly provided by Istituto Sieroterapico e Vaccinogeno Sclavo, Siena, Italy. TES antigen(s), routinely used for serodiagnostic test for visceral larva migrans, was prepared as described by De Savigny (14). Human IFN- $\gamma$, IL-2, IL-4, and IL-5 oligonucleotide probes were purchased from Amgen Biologicals.

Generation of antigen-specific $T$ cell lines (TCL) and TCC. Antigenspecific TCL were generated according to a technique previously described (15). Briefly, $10^{6}$ PBMC in $2 \mathrm{ml}$ RPMI 1640 medium supplemented with $2 \mathrm{mM}$ L-glutamine, $20 \mu \mathrm{M}$ 2-mercaptoethanol, and 5\% human serum (complete medium) were stimulated with TES or PPD ( 1 $\mu \mathrm{g} / \mathrm{ml})$ in 24-well flat-bottomed plates for $5 \mathrm{~d}$. Human rIL-2 $(20 \mathrm{U} / \mathrm{ml})$ was then added and cultures continued for additional $7 \mathrm{~d}$. Viable $\mathrm{T}$ blasts were resuspended in complete medium and tested for their antigen specificity before cloning procedure. To assess the antigen specificity of TCL, $4 \times 10^{4} \mathrm{~T}$ blasts were seeded in microplates and cocultured for $48 \mathrm{~h}$ with irradiated $(5,000 \mathrm{rad})$ autologous PBMC $\left(8 \times 10^{4}\right)$ in the presence of medium alone, TES $(1 \mu \mathrm{g} / \mathrm{ml}), \operatorname{PPD}(1 \mu \mathrm{g} / \mathrm{ml})$, or PHA $(1 \%$ $\mathrm{vol} / \mathrm{vol}$ ). After a 16 -h pulse with $0.5 \mu \mathrm{Ci}{ }^{3} \mathrm{H}$-TdR, cultures were harvested and radioactivity measured by liquid scintillation. To generate TES-specific or PPD-specific TCC, T blasts obtained from antigen-specific TCL were seeded under limiting dilution conditions $(0.3$ cell/well) in round-bottomed microwells containing $10^{5}$ irradiated allogeneic spleen cells (as feeder cells) and PHA (1\% vol/vol) in a final vol of 0.2 $\mathrm{ml}$ complete medium supplemented with rIL-2 $(20 \mathrm{U} / \mathrm{ml})$ and $10 \%$ FCS (Hyclone Laboratories, Inc., Logan, UT), as reported elsewhere (9, 16). Growing microcultures were then supplemented, at weekly intervals, with rIL-2 $(20 \mathrm{U} / \mathrm{ml})$ and $10^{5}$ irradiated feeder cells. The phenotype of T blasts of TCL and TCC was examined by flow cytometry. The antigen specificity of TCC was assessed by measuring ${ }^{3} \mathrm{H}-\mathrm{TdR}$ uptake after $60 \mathrm{~h}$ stimulation with the appropriate antigen under MHC-restricted conditions, as reported above. When stimulation index (ratio between the mean counts per minute obtained in cultures stimulated with antigen-presenting cells plus antigen and the mean counts per minute obtained in cultures with antigen-presenting cells alone) was $>20$, responses were considered as positive.

Induction of cytokine production by antigen-specific TCC. To induce the cytokine production by stimulation with the appropriate antigen, $10^{6} \mathrm{~T}$ blasts from each TCC were cocultured in $1 \mathrm{ml}$ complete medium with $5 \times 10^{5}$ irradiated autologous non-T cells (16) in the presence of either TES or PPD $(1 \mu \mathrm{g} / \mathrm{ml})$. After $48 \mathrm{~h}$, culture supernatants (SN) were collected, filtered, and stored in aliquots at $-70^{\circ} \mathrm{C}$ until used. To induce cytokine production by nonspecific activation, TCC were resuspended at $10^{6} / \mathrm{ml}$ complete medium and cultured in the presence of PMA $(10 \mathrm{ng} / \mathrm{ml})$ plus anti-CD3 MAb $(200 \mathrm{ng} / \mathrm{ml})$. After 36 $\mathrm{h}$, culture $\mathrm{SN}$ were collected, filtered, and stored in aliquots at $-70^{\circ} \mathrm{C}$ until used.

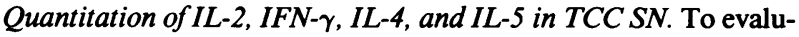
ate the ability of TCC to produce IL-2, $0.2 \mathrm{ml} \mathrm{SN}$ was added at different concentrations $(1 / 2$ to $1 / 40)$ to $4 \times 10^{3}$ indicator cells (CTLL-2 murine cells line), as previously described $(9,16)$. A semiquantitative estimate of IL-2 produced by each TCC was obtained by a standard curve of rIL-2. The quantitative determinations of IFN- $\gamma$ and IL-4 were performed by a commercial RIA (Centocor Inc., Malvern, PA) and ELISA (Quantikine Immunoassays, R \& D Systems, Inc., Minneapolis, MN), respectively. For the measurement of human IL-5, the murine LyH7.B13 cell line was used as a source of indicator cells (kind gift of Dr. R. Palacios, Basel, Switzerland) (17). A semiquantitative estimate of IL-5 produced by TCC was obtained by a standard curve of human rIL-5. TCC SN showing IFN- $\gamma$, IL-2, IL-4, or IL-5 levels 3 SD over the mean levels in control SN derived from irradiated non-T cells alone, were regarded as positive.

Slot hybridization analysis of IFN- $\gamma, I L-2, I L-4$, and IL-5 RNA expression. To assess the expression in TCC of cytokine RNA upon stimulation with PMA plus anti-CD3 MAb, the method originally described by White and Bancroft (18) was used as detailed elsewhere (10). Prehybridization of the nylon membrane, preparation by '5-end-labelling technique of the ${ }^{32} \mathrm{P}$-labelled human IFN- $\gamma$, IL-2, IL-4, and IL-5 oligonucleotide probes (sp act 1-2 $11^{8} \mathrm{cpm} / \mathrm{ng}$ ), hybridization and autoradiography were performed as described by Sambrook et al. (19).

Southern-blot analysis of $T$ cell receptor (TCR) gene rearrangements. High mol wt DNA was prepared from eight PPD- and eight TES-specific randomly selected TCC derived from the same donor (CM), according to standard procedures (19). Digestion of DNAs with EcoRI (Boehringer Mannheim GmbH, Mannheim, Germany) was performed according to the manufacturer's instructions. DNAs were fractionated by gel electrophoresis on $0.8 \%$ agarose gel, transferred to Gene Screen Plus filters (New England Nuclear, Boston, MA), and hybridized with DNA probe for TCR $\beta$ (Oncor, Inc., Gaithersburg, $\mathrm{MD}$ ), radiolabelled with [ $\left.\alpha^{32} \mathrm{P}\right] \mathrm{dCTP}$ by nick translation (sp act $0.5-1$ $\times 10^{9}$ ). Germ-line configuration was obtained using DNA extracted from a polyclonal $\mathrm{T}$ cell line digested with EcoRI (Oncor).

\section{Results}

Induction of TES-specific and PPD-specific TCC. PBMC from two healthy individuals were stimulated for $5 \mathrm{~d}$ with TES or PPD and growing $T$ blasts expanded with IL-2 for an additional $7 \mathrm{~d}$. The TCL so obtained were then assessed for their ability to proliferate in response to TES or PPD, respectively. Both TESspecific and PPD-specific TCL exhibited strong proliferation in response to the appropriate antigen in the presence of autologous irradiated PBMC. T blasts from TES- and PPD-specific TCL were then cloned in the presence of irradiated feeder cells, PHA, and IL-2. A total number of 50 and $39 \mathrm{CD4}^{+}$TCC were obtained from the two TES-specific TCL, whereas $\mathrm{CD}^{+}$TCC obtained from the two PPD-specific TCL were 46 and 22, respectively. 69 out of 89 TCC derived from the two TES-specific TCL exhibited strong proliferation (mitogenic index $>20$ ) in response to an appropriate concentration of TES $(1 \mu \mathrm{g} / \mathrm{ml})$ under MHC-restricted conditions. Likewise, under the same MHC-restricted conditions, 60 out of 68 TCC derived from the two PPD-specific TCL proliferated in response to PPD $(1 \mu \mathrm{g} /$ $\mathrm{ml})$. The remaining $28 \mathrm{TCC}$ did not proliferate in response to either TES or PPD (mitogenic index $<2$ ), but showed strong proliferation to PHA (data not shown). Molecular analysis of TCR $\beta$ configuration, performed in eight PPD- and eight TESspecific randomly selected TCC derived from the same donor, 
$\mathrm{Kb}$

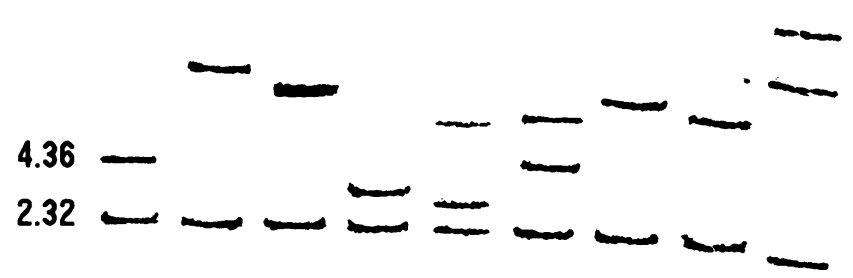

G

$$
\frac{[\text { CM2 CM14 CM18 CM33 }}{\text { TES-spectific TCC }} \frac{\text { CM1 CM6 CM11 CM41 }}{\text { PPD-specific TCC }}
$$

Figure 1. Molecular analysis of TCR $\beta$ gene configuration in eight representative TCC (four specific for PPD and four specific for TES) derived from donor CM. Southern blot analysis of TCR $\beta$ gene configuration was performed on the DNAs obtained from the eight TCC, as described in Methods. All TCC showed TCR $\beta$ gene rearrangement as compared with the germ line configuration $(G)$ and each of them showed an individual pattern of rearrangement.

showed individual patterns of TCR $\beta$ gene rearrangements (Fig. 1 ), suggesting the independent origin of TCC studied.

Cytokine profiles of TES-specific and PPD-specific TCC. The profiles of cytokine secretion in response to stimulation with the appropriate antigen of TES- and PPD-specific TCC were then analyzed and compared. To this end, $T$ blasts from each TES- or PPD-specific TCC were stimulated for $48 \mathrm{~h}$ with optimal antigen concentration in the presence of irradiated autologous non-T cells and culture SN assayed for their cytokine content. As shown in Fig. 2, most TES-specific TCC secreted substantial amounts of IL- 4 and IL-5, but not, or limited amounts of, IL-2 and IFN- $\gamma$. Only four of them, in addition to IL-4 and IL-5, produced substantial amounts of IFN- $\gamma$ (Th0like phenotype). In contrast, stimulation with PPD induced all PPD-specific TCC to secrete high amounts of IL-2 and/or IFN$\gamma$, but not IL-4 or IL-5, with the exception of two. Both TCC produced IL- 4 and one of them IL-5, as well (Th0-like phenotype).
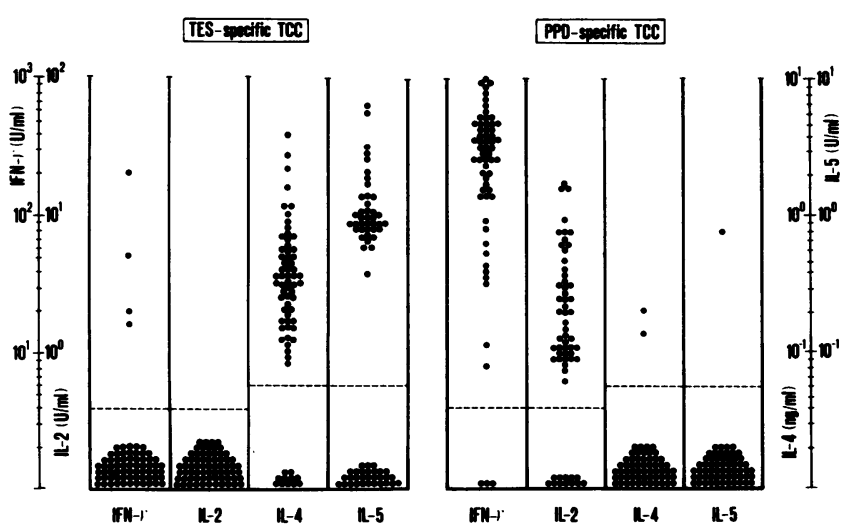

Figure 2. Cytokine production by TES-specific and PPD-specific TCC in response to stimulation with the appropriate antigen. $T$ blasts from each TCC were washed, counted, and incubated at $10^{6} / \mathrm{ml}$ in the presence of $5 \times 10^{5} / \mathrm{ml}$ irradiated autologous non-T cells, as APC, and the appropriate antigen $(1 \mu \mathrm{g} / \mathrm{ml})$. After $48 \mathrm{~h}$, culture supernatants were recovered and assayed for their cytokine content as described in Methods. Dotted lines represent 3 SD values over the mean cytokine content of culture supernatants of irradiated non-T cells alone.
Table I. Distribution of TES- and PPD-specific TCC According to Their Profile of Cytokine Production in Response to Stimulation with PMA plus anti-CD3 Antibody*

\begin{tabular}{lcccc}
\hline \multirow{2}{*}{$\begin{array}{c}\text { Antigen- } \\
\text { specificity } \\
\text { of TCC }\end{array}$} & $\begin{array}{c}\text { No. of } \\
\text { TCC }\end{array}$ & \multicolumn{3}{c}{ Th subset distribution $^{*}$} \\
\cline { 3 - 5 } & Th1 & Th2 & Th0 \\
\hline PPD & $(60)$ & $46(77 \%)$ & $0(-)$ & $14(23 \%)$ \\
TES & $(69)$ & $0(-)$ & $43(62 \%)$ & $26(38 \%)$ \\
Unknown $^{5}$ & $(28)$ & $7(25 \%)$ & $4(14 \%)$ & $17(61 \%)$
\end{tabular}

* Clonal T blasts $\left(10^{6} / \mathrm{ml}\right)$ were stimulated for $36 \mathrm{~h}$ with PMA (10 $\mathrm{ng} / \mathrm{ml})$ plus anti-CD3 MAb (200 ng/ml) and cytokines secreted into supernatant were quantitated by appropriate assays, as described in Methods. ${ }^{\ddagger}$ TCC able to produce IL- 2 and IFN- $\gamma$, but not IL-4 and IL-5, were defined as Th1; TCC able to produce IL-4 and IL-5, but not IL-2 and IFN- $\gamma$, were defined as Th2; TCC able to produce at the same time IL- 2 and IL- 4 or IL-5 or IFN- $\gamma$, and IL- 4 or IL-5, were defined as Th0. ${ }^{5}$ TCC that failed to proliferate (mitogenic index $<2$ ) in response to either PPD or TES in the presence of irradiated autologous non-T cells.

The great majority of both TES- and PPD-specific TCC retained their profile of cytokine secretion even upon maximal stimulation, such as that provided by PMA plus anti-CD3 MAb. Under these experimental conditions 77\% of PPD-specific TCC expressed a Th1- and $23 \%$ a Th0-like phenotype, whereas $62 \%$ of TES-specific TCC expressed a Th2- and 38\% a Th0-like phenotype. No Th2-like phenotype among PPD-specific TCC and no Th1-like phenotype among TES-specific TCC were found. In contrast, under the same experimental conditions, $61 \%$ of 28 TCC with unknown specificity expressed a Th0-, 25\% a Th1-, and 14\% a Th2-like phenotype (Table I). The definite Th2- and Th1-like profiles of TES- and PPD-specific TCC was confirmed at RNA level. A number of randomly selected TES-specific TCC that failed to produce IFN- $\gamma$ and a number of PPD-specific TCC that failed to produce IL-4 and IL-5 upon stimulation with PMA plus anti-CD3 MAb were found by slot-blot analysis to lack RNA transcripts for IFN- $\gamma$ or for IL-4 and IL-5, respectively (Fig. 3). During the course of this study, over a period of 6 mo, the phenotypes of 15 Th1and of $12 \mathrm{Th} 2$-like clones were repeatedly assessed and remained constant (data not shown).

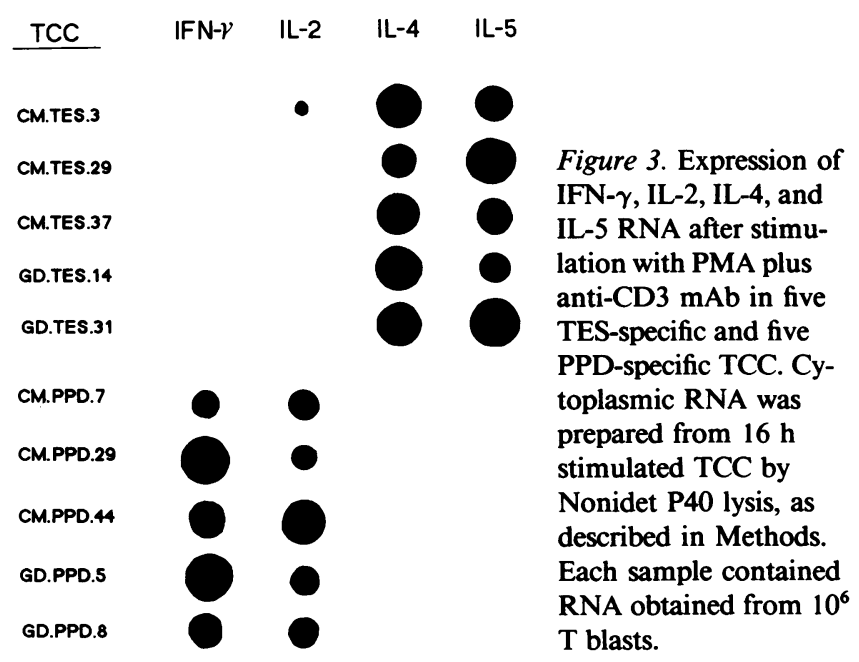




\section{Discussion}

The results of this study demonstrate that TCC specific for a bacterial antigen (PPD) or a helminth component (TES) established in vitro from the $\mathrm{PB}$ of the same individual belong to subsets of $\mathrm{CD}^{+} \mathrm{T}$ cells with opposite (Th1- or Th2-like, respectively) and stable profile of cytokine production. Unlike the alloreactive human TCC described by Paliard et al. (6), the PPD- and TES-specific TCC reported here had a profile of cytokine production only partially dependent on the stimulant used. When TCC were stimulated with PMA plus anti-CD3 antibody, the majority of TCC retained the antigen-revealed phenotype. A proportion of Th1 and Th2 shifted to the Th0 phenotype, probably because the combined activity of PMA and anti-CD3 antibody resulted in a stronger stimulation for $T$ cells than that induced by the specific antigen. However, shifting from $T h 0$ to $T h 1$ or $T h 2$, from $T h 1$ to $T h 2$, or from $T h 2$ to Th1, was never observed.

The fact that PPD-specific TCC belong to the Th1-like subset (producing IL-2 and IFN- $\gamma$ ) may explain why in vivo Mt infection usually results in the development of remarkable DTH towards this antigen. Production of IFN- $\gamma$ is indeed essential for the expression of DTH reactions (20). The finding that the great majority of TES-specific $T$ cell clones isolated from the PB of healthy individuals belong to the Th2-like subset is also of interest. Human infection with Tc may result in visceral larva migrans or ocular toxocariasis, which usually associate with increased IgE levels and eosinophilia (13). Thus, the finding that TES-specific TCC usually produce IL-4 and IL-5, but not IFN- $\gamma$, may account for both IgE production and increase of eosinophils in Tc-infected patients.

The mechanisms by which in the same individual TES expands Th2-like, whereas PPD expands Th1-like T cells remain to be determined. In the mouse infested with Schistosoma mansoni a $\mathrm{Th} 2$ response was shown to be induced by parasite eggs and directed largely against egg antigens, whereas the Th1 reactivity in vaccinated mice was triggered primarily by larval antigens (21). Thus, a first possibility may be that physical and/ or chemical properties of antigens are responsible for the preferential activation of one or the other subset. For example, it has recently been shown that polyphenol-rich compounds preferentially activate Th2 cells (22). How such properties may influence $\mathrm{T}$ cell response is unclear, but might involve the preferential use of different accessory cells for antigen presentation. In mouse, both $\mathrm{Th} 1$ and $\mathrm{Th} 2$ cells respond comparably to macrophages, but $\mathrm{Th} 2$ clones respond better to B cells than Th1 clones (23). Hepatic nonparenchymal cells, enriched for Kupffer cells of macrophage/monocyte origin, stimulate optimal proliferation of Th1 but not Th2 clones (24). Murine brain capillary endothelial cells are more effective at stimulating Th2 clones, whereas brain capillary smooth muscle cells preferentially stimulate Th1 proliferation (25). Such data strongly support the notion that $\mathrm{Th} 1$ and $\mathrm{Th} 2$ clones have distinct requirements for proliferative signals provided by APC. If this is the case, it is reasonable to suggest that $\mathrm{Mt}$ and $\mathrm{Tc}$ antigens are processed by functionally distinct APC.

Additional influences may result from steroid hormone control over the anatomic compartmentalization of T cell lymphokine production (26) and from the regulatory activity of lymphokines themselves (26-29). In the murine leishmaniasis model, IFN- $\gamma$ can strongly influence activated $\mathrm{CD} 4^{+} \mathrm{T}$ cells to differentiate into cells that produce the Th1 set of cytokines, and IL-4 may be the counterpart that promotes Th2 differentiation of the same precursors (28). Another type of cross-regulation may be provided by IL-10, which is produced by $\mathrm{Th} 2$, but not Th 1 clones, and inhibits the cytokine synthesis by Th1 cells (29).

Whatever mechanism is involved, our data provide undoubted evidence that, not only in mice but also in humans, immunization with different infectious agents may involve dominant Th1 or Th 2 cytokine patterns. Future experiments may reveal why, at least in some conditions, DTH responses and responses characterized by IgE antibody production and eosinophilia appear to be mutually exclusive rather than coexistent.

\section{Acknowledgments}

Special thanks to Dr. Ronald Palacios for providing the LyH7.B13 cell line for these studies.

This work was supported in part by grant 91.00227.PF41 from the Consiglio Nazionale delle Ricerche Targeted Project "Prevention and Control of Disease Factors" SP2, in part by grant 12-02-01855 from Ministero dell'Università e della Ricerca Scientifica e Tecnologica, and in part by a grant from Associazone Italiana per la Ricerca sul Cancro.

\section{References}

1. Mosmann, T. R., H. Cherwinski, M. W. Bond, M. A. Giedlin, and R. L. Coffman. 1986. Two types of murine helper T cell clone. I. Definition according to profiles of lymphokine activities and secreted proteins. J. Immunol. 136:23482357.

2. Coffman, R. L., B. W. Seymour, D. A. Lebman, D. D. Hiraki, J. A. Christiansen, B. Shrader, H. M. Cherwinsky, H. F. Savelkoul, F. D. Finkelman, M. W. Bond, and T. R. Mosmann. 1988. The role of helper T cell products in mouse B cell differentiation and isotype regulation. Immunol. Rev. 102:5-28.

3. Firestein, G. S., W. D. Roeder, J. A. Laxer, K. S. Townsend, C. T. Weaver, J. T. Hom, J. Linnton, B. E. Torbett, and A. L. Glasebrook. 1989. A new murine $\mathrm{CD}^{+} \mathrm{T}$ cell subset with an unrestricted cytokine profile. J. Immunol. 143:518525.

4. Street, N. E., J. H. Schumacher, T. A. T. Fong, H. Bass, D. F. Fiorentino, J. A. Leverah, and T. R. Mosmann. 1990. Heterogeneity of mouse helper T cells. Evidence from bulk cultures and limiting dilution cloning for precursors of $\mathrm{Th} 1$ and Th2 cell. J. Immunol. 144:1629-1639.

5. Swain, S. L., A. D. Weinberg, and M. English. 1990. CD4 ${ }^{+}$T cell subsets: lymphokine secretion of memory cells and of effector cells which develop from precursors in vitro. J. Immunol. 144:1788-1799.

6. Pallaird, X., R. de Waal Malefijt, H. Yssel, D. Blanchard, I. Chretien, J. Abrams, J. E. de Vries, and H. Spits. 1988. Simultaneous production of IL-2, IL-4, and IFN- $\gamma$ by activated human $\mathrm{CD}^{+}$and $\mathrm{CD}^{+} \mathrm{T}$ cell clones. J. Immunol. 141:849-855.

7. Maggi, E., G. F. Del Prete, D. Macchia, P. Parronchi, A. Tiri, I. Chretien, M. Ricci, and S. Romagnani. 1988. Profiles of lymphokine activities and helper function for IgE in human T cell clones. Eur. J. Immunol. 18:1045-1050.

8. Del Prete, G. F., A. Tiri, M. De Carli, S. Mariotti, A. Pinchera, I. Chretien, S. Romagnani, and M. Ricci. 1989. High potential to tumor necrosis factor- $a$ (TNF- $\alpha$ ) production of thyroid infiltrating T lymphocytes in Hashimoto's thyroiditis: a peculiar feature of destructive thyroid autoimmunity. Autoimmunity. 4:267-276.

9. Del Prete, G. F., A. Tiri, E. Maggi, M. De Carli, D. Macchia, P. Parronchi, M. E. Rossi, M. C. Pietrogrande, M. Ricci, and S. Romagnani. 1989. Defective in vitro production of $\gamma$-interferon and tumor necrosis factor- $\alpha$ by circulating $T$ cells from patients with the hyperimmunoglobulin E syndrome. J. Clin. Invest. 84:1830-1835.

10. Maggi, E., P. Biswas, G. F. Del Prete, P. Parronchi, D. Macchia, C. Simonelli, L. Emmi, M. De Carli, A. Tiri, M. Ricci, and S. Romagnani. 1991. Accumulation of Th2-like helper $T$ cells in the conjunctiva of patients with vernal conjunctivitis. J. Immunol. 146:1169-1174.

11. Wierenga, E. A., M. Snoek, C. de Groot, I. Chretien, J. D. Bos, H. M. Jansen, and M. Kapsemberg. 1990. Evidence for compartimentalization of functional subsets of CD4 T lymphocytes in atopic patients. J. Immunol. 144:46514656.

12. Maizels, R. M., M. W. Kennedy, M. Meghji, B. D. Robertson, and H. V. 
Smith. 1987. Shared carbohydrate epitopes on distinct surface and secreted antigens of the parasitic nematode Toxocara canis. J. Immunol. 139:207-214.

13. Ogilvie, B. M., and D. De Savigny. 1982. Immune response to nematodes In Immunology of Parasitic Infections. S. Cohen and K. S. Warren, editors. Blackwell Scientific Publications, Ltd., Oxford. 715-757.

14. De Savigny, D. H. 1975. In vitro maintenance of Toxocara canis larvae and a simple method for the production of Toxocara ES antigen for use in serodiagnostic tests for visceral larva migrans. J. Parasitol. 61:781-789.

15. Lanzavecchia, A., P. Santini, E. Maggi, G. F. Del Prete, P. Falagiani, S. Romagnani, and M. Ferrarini. 1983. In vitro selective expansion of allergen specific T cells from atopic patients. Clin. Exp. Immunol. 52:21-28.

16. Del Prete, G. F., E. Maggi, P. Parronchi, I. Chretien, A. Tiri, D. Macchia M. Ricci, J. Banchereau, J. de Vries, and S. Romagnani. 1988. IL-4 is an essentia factor for the IgE synthesis induced in vitro by human $\mathrm{T}$ cell clones and their supernatants. J. Immunol. 140:4193-4198.

17. Rolink, A. G., F. Melchers, and R. Palacios. 1989. Monoclonal antibodies reactive with the mouse interleukin 5 receptor. J. Exp. Med. 169:1693-1701.

18. White, B. A., and F. C. Bancroft. 1982. Cytoplasmic dot hybridization: simple analysis of relative mRNA in multiple small cell or tissue samples. J. Biol. Chem. 257:8569-8572.

19. Sambrook, J., E. F. Fritsch, and T. Maniatis. 1989. Molecular Cloning: A Laboratory Manual. 2nd ed. Vol. I, chap. 7. Cold Spring Harbor Laboratory, Cold Spring Harbor, NY.

20. Fong, T. A. T., and T. R. Mosmann. 1989. The role of IFN- $\gamma$ in delayed type hypersensitivity mediated by Thl clones. J. Immunol. 143:2887-2893.

21. Pearce, E. J., P. Caspar, J-M. Grzych, F. A. Lewis, and A. Sher. 1991 Downregulation of Th1 cytokine production accompanies induction of $\mathrm{Th} 2 \mathrm{re}$ - sponses by a parasitic helminth, Schistosoma mansoni. J. Exp. Med. 173:159166.

22. Baum, C. G., P. Szabo, G. W. Siskind, C. G. Becker, A. Firpo, C. J. Clarick, and T. Francus. 1990. Cellular control of IgE induction by a polyphenolrich compound. J. Immunol. 145:779-784.

23. Chang, T-L., C. L. Shea, S. Urioste, R. C. Thompson, W. H. Boom, and A. K. Abbas. 1990. Heterogeneity of helper/inducer T lymphocytes. III. Responses of IL-2 and IL-4 producing (Th1 and Th2) clones to antigens presented by different accessory cells. J. Immunol. 145:2803-2808.

24. Magilavy, D. B., F. W. Fitch, and T. F. Gayewski. 1989. Murine hepatic accessory cells support the proliferation of Th1 but not $\mathrm{Th} 2$ helper $\mathrm{T}$ lymphocyte clones. J. Exp. Med. 170:985-990.

25. Fabry, Z., M. Sandor, T. F. Gayewsky, R. Lynch, and M. Hart. 1990. $\mathrm{CD4}^{+} \mathrm{T}$ cell subsets are differentially activated when the antigen is presented by murine brain capillary endothelium versus smooth muscle cells. FASEB (Fed. Am. Soc. Exp. Biol.) J. 4:1802A. (Abstr.)

26. Daynes, R. A., B. A. Araneo, T. A. Dowel, K. Huang and D. Dudley. 1990. Regulation of murine lymphokine production in vitro. III. The lymphoid tissue microenvironment exerts regulatory influences over helper T-cell function. J. Exp. Med. 171:979-996.

27. Swain, S. L. A. D. Weinberg and G. Huston. 1990. IL-4 and IFN- $\gamma$ direct the development of distinct subsets of helper T cells. Fed. Proc. 4:2020A. (Abstr.)

28. Coffman, R. L., R. Chatelain, L. M. C. C. Leal, and K. Varkila. 1991 Leishmania major infection in mice: a model system for the study of $\mathrm{CD}^{+} \mathrm{T}$ cell subset differentiation. Res. Immunol. In press.

29. Fiorentino, D. F., M. W. Bond, and T. R. Mosmann. 1989. Two types of mouse T helper cell. IV. Th2 clones secrete a factor that inhibits cytokine production by Th1 clones. J. Exp. Med. 170:2081-2095. 